C2006 IEEE. Personal use of this material is permitted. However, permission to reprint/republish this material for advertising or promotional purposes or for creating new collective works for resale or redistribution to servers or lists, or to reuse any copyrighted component of this work in other works must be obtained from the IEEE. 


\title{
Context and Time Dependent Risk Based Decision Making
}

\author{
Omar Khadeer Hussain ${ }^{1}$, Elizabeth Chang ${ }^{1}$, Farookh Khadeer Hussain ${ }^{1}$, Tharam S. Dillon ${ }^{2}$ and Ben Soh ${ }^{3}$ \\ ${ }^{1}$ School of Information Systems, Curtin University of Technology, Perth, Australia \\ \{Omar.Hussain, Elizabeth.Chang, Farookh.Hussain\}@cbs.curtin.edu.au \\ ${ }^{2}$ Faculty of Information Technology, University of Technology, Sydney, Australia \\ tharam@it.uts.edu.au \\ ${ }^{3}$ Dept of Computer Science and Computer Engineering, La Trobe University, VIC, Australia \\ ben@cs.latrobe.edu.au
}

\begin{abstract}
As there is a lack of central management in an ecommerce interaction carried out based on peer-topeer architecture, it is obvious for the trusting peer to analyze the Risk beforehand that could be involved in dealing with a trusted peer in these types of interactions. Another characteristic of peer-to-peer architecture interactions is that the trusting peer might have to choose a peer to interact with, from a set of possible trusted peers. It can ease its decision making process of choosing a peer to interact with by analyzing the Risk that could be involved in dealing with each of the possible trusted peers. In this paper we highlight and propose a solution to this problem by which the trusting peer can decide with which peer to interact with after analyzing the Risk that could be associated in dealing with each of them.
\end{abstract}

\section{Introduction}

In a Peer-to-Peer financial interaction there is always an element of doubt in the trusting peer's mind regarding the safety of its resources involved in the interaction. This element of doubt is termed as Risk in the interaction [1]. Risk is a combination of:

a) The uncertainty of the outcome and

b) The cost of the outcomes when it occurs, usually the loss incurred, which is related to Risk.

Hence Risk should be identified and analyzed before engaging in any activity in order to manage it better and to protect the resources involved in the interaction. The Australian and New Zealand Standard on Risk Management, AS/NZS 4360:2004 too states that Risk Identification is the heart of Risk Management [2]. The inclusion of Risk in the study of behavior in e-commerce transactions is important because there is a large volume of literature based in rational economics that argues that the decision to proceed with the transaction is based on the Risk adjusted cost benefit analysis [3] and analyzing Risk in the transaction is really important with the widespread use of the Internet, particularly with the advent of business and e-commerce transactions. Thus it commands a central role in any discussion of ecommerce that is related to a transaction.

Hence in order to analyze and measure Risk in an interaction, we defined the term Riskiness in Hussain et al [4]. Riskiness is defined as the numerical value that is assigned by the trusting peer to the trusted peer after the interaction, which shows its level of Risk on the Riskiness scale. The Riskiness scale as shown in figure 1 contains different levels of Risk that could be present in an interaction. The Riskiness value assigned to the trusted peer by the trusting peer is dependent on the level of un-commitment in the actual behavior of the trusted peer with respect to the expected behavior. Since the Riskiness value shows the level of Risk on the Riskiness scale, any peer can get an indication of the Risk that could be present in interacting with a particular trusted peer by analyzing its Riskiness value in the particular context of the interaction.

We have defined a methodology in Hussain et al [5] by which the trusting peer can analyze the Riskiness of a trusted peer beforehand according to the context, criteria and time of its interaction. In this paper we will extend the proposed methodology and propose a solution to the problem where the trusting peer has to choose a peer to interact with from a set of possible trusted peers, after analyzing the Risk that could be involved in dealing with each possible trusted peer.

\section{Related Work}

In a Peer-to-Peer interaction the trusting peer might have to decide from a set of possible trusted peers with whom to interact with. If the trusting peer has not 


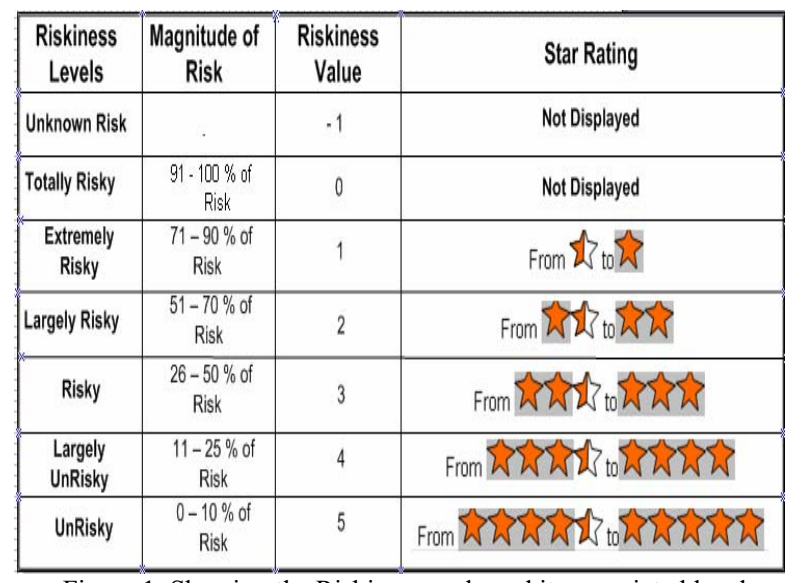

Figure 1. Showing the Riskiness scale and its associated levels

interacted with any of the possible trusted peers before then it doesn't know the level of Risk that could be present in interacting with any of them and hence it would be difficult for it to decide on with which trusted peer to interact with. A solution to this would be the trusting peer to assess the Risk involved in dealing with each of the trusted peers according to the context, time and criteria of the trusting peer's interaction. Depending on the analysis the trusting peer can easily decide with which trusted peer to interact with.

The trusting peer can analyze the Risk involved in dealing with the possible trusted peers by soliciting recommendations from other peers according to the context of its interaction. It issues a reputation query soliciting for recommendations for the possible trusted peers along with specifying the context of its interaction. The peers giving recommendations are known as the Recommending peers. The peers who had interacted with the possible trusted peers before in the same context, in which the trusting peer is asking for recommendations, reply back with their recommendation in the form of a Risk set. As discussed in Hussain et al [6], Risk set is a standard format for soliciting recommendations by the recommending peers so that it is easier for the trusting peer to interpret and understand them. The Risk set contains the recommended Riskiness value which the recommending peer recommends for the trusted peer. This Riskiness value which the recommending peer recommends is based on its previous interaction with the trusted peer in question and hence is according to the criteria of the recommending peer's interaction. Consequently it is possible that a recommendation of a recommending peer for a particular trusted peer might not be beneficial to the trusting peer asking for recommendations, if the criteria of their interaction are not similar. Additionally the trusting peer while assimilating the recommendations should also consider the following:

1. The time spot at which the recommending peer interacted with the trusted peer. As mentioned in Hussain et al [5], Risk is dynamic and hence the trusting peer should give more weight to recommendations which are in the same time slot.

2. Recommendations from peers who are either trustworthy or unknown recommenders and discard the recommendations from those peers who give untrustworthy recommendations. The process of classifying the recommendations as trustworthy or untrustworthy is discussed in Hussain et al [7]. To summarize the concept, a peer whose Riskiness value while giving recommendations is within the range of $(-1,1)$ is said to be giving trustworthy recommendations.

Hence in order for the trusting peer to decide on with which trusted peer to interact with it should consider all these scenarios when it assimilates the recommendations and determines the Riskiness value of each possible trusted peer. In order to get a better understanding of the problem definition, let us consider that a trusting peer ' $A$ ' wants to interact with a peer in the context of transporting its goods from one place to another and the criteria of the trusting peer in the interaction are $\mathrm{C} 1, \mathrm{C} 2$ and $\mathrm{C} 3$. The trusting peer ' $\mathrm{A}$ ' has not interacted before in this context with any trusted peer and hence broadcasts its request of transporting its goods. Let us suppose that it gets replies from peers ' $\mathrm{B}$ ' and ' $\mathrm{C}$ ' who are willing to fulfill trusting peer ' $A$ ' request. These peers are the set of possible trusted peers from which the trusting peer has to decide and choose one of them to interact with. Since the trusting peer has not interacted with any of the possible trusted peers before, it does not know the Risk that could be associated in dealing with any of them. Hence in order to analyze the Risk involved in dealing with each possible trusted peer and ease its process of decision making, it solicits for recommendation from other peers. The peers who had interacted with the possible trusted peers in question reply back with their recommendations in the form of Risk set as discussed in Hussain et al [6].

After getting the recommendations, the trusting peer should assimilate the recommendations according to its criteria, time and trustworthiness to determine the Riskiness value of the possible trusted peers accordingly. Based on the Riskiness value achieved for the trusted peers, the trusting peer can then decide with which peer to interact with.

As discussed before the recommendation from a recommending peer for a particular trusted peer might not be of any use to the trusting peer asking for recommendations, if the criteria of their interaction are 
not similar. Hence the trusting peer should consider only those recommendations whose criterions are similar to those in its interaction and determine the Riskiness value of the trusted peers in each criterion according to those recommendations. It can then determine the final Riskiness value of each trusted peer by weighting the Riskiness value of each criterion according to the significance of the criterions.

The Riskiness value of a particular trusted peer ' $\mathrm{P}$ ' in a criterion $\mathrm{C}\left(\mathrm{R}_{\mathrm{PC}}\right)$ can be determined after assimilating the recommendations by using the following formulae:

Riskiness value of the trusted peer ' $\mathrm{P}$ ' in Criterion $\mathrm{C}\left(\mathrm{R}_{\mathrm{PC}}\right)=$

$$
\begin{aligned}
& \left(\alpha * \left(\left(\frac{1}{N} * \mid \gamma *\left(\sum_{i=1}^{N} \operatorname{RRP}_{\mathrm{i}} * \text { Commitment Level }_{\mathrm{c}}\right) \mid\right)+\right.\right. \\
& \left.\left.\left(\frac{1}{K} * \mid \delta *\left(\sum_{l=1}^{K} \mathrm{RRP}_{1} * \text { Commitment Level }_{\mathrm{c}}\right) \mid\right)\right)\right) \\
& + \\
& \left(\beta * \left(\left(\frac{1}{J} * \gamma\left(\sum_{o=1}^{J} \text { Commitment Level }_{\mathrm{c}}\right)\right)+\right.\right. \\
& \left.\left.\left(\frac{1}{M} * \delta\left(\sum_{q=1}^{M} \text { Commitment Level } \mathrm{c}_{\mathrm{c}}\right)\right)\right)\right)
\end{aligned}
$$

\section{Equation----1}

where $R R P_{i}$ is the Riskiness value of the trustworthy recommending peer $i$ whose recommendation is in the recent time slot of the trusting peer's interaction ,

$\mathrm{RRP}_{1}$ is the Riskiness value of the trustworthy recommending peer 1 , whose recommendation is in the far recent time slot of the trusting peer's interaction,

Commitment level ${ }_{c}$ is the level of commitment by the trusted peer in the particular criterion ' $c$ ' as recommended by the recommending peer in its recommendations,

$\mathrm{N}$ and $\mathrm{K}$ are the number of trustworthy recommendations classified according to the recent and far recent time slots respectively,

$\mathrm{J}$ and $\mathrm{M}$ are the number of unknown recommendations classified according to the recent and far recent time slots respectively,

$\gamma$ and $\delta$ are the weights attached to the parts of the equation which give more weight to recommendations which are in the recent time slot as compared to the far recent ones. In general $\gamma>\delta$ and $\gamma+\delta=1$,

$\alpha$ and $\beta$ are the weights attached to the parts of the equation which will give more weight to the recommendation from the trustworthy recommending peers as compared to the unknown recommending peers. In general $\alpha>\beta$ and $\alpha+\beta=1$.

The Riskiness value determination of the trusted peer ' $\mathrm{P}$ ' in a criterion ' $\mathrm{C}$ ' is done in two parts as shown in equation 1. The first part of the equation calculates the Riskiness value of the trusted peer ' $\mathrm{P}$ ' in a criterion ' $\mathrm{C}$ ' by taking the recommendations of the trustworthy recommending peers and the second part calculates the Riskiness value of the same trusted peer in the same criterion by taking the recommendations of the unknown recommending peers. The recommendations from the un-trustworthy recommending peers are left out and not considered. Further the Riskiness value determination of the trusted peer ' $\mathrm{P}$ ' in a criterion ' $\mathrm{C}$ ' by taking the recommendations from the trustworthy and unknown recommending peers too is done in two parts according to the time slot of the recommendations. The trusting peer gives more weight to the recommendations which are in the recent time slot of its interaction as compared to the far recent time slot recommendations. Those weights are represented by $\gamma$ and $\delta$ respectively. In order to give more importance to the recommendations from the trustworthy recommending peers as compared to the recommendations from the unknown recommending peers, weights are attached to the two parts of the equation. These weights are represented by $\alpha$ and $\beta$ respectively. It depends upon the trusting peer on how much weight does it want to give to each recommendation. By multiplying the Riskiness value of the trustworthy recommending peer (RRP) with the commitment level that it is suggesting for a criterion, an accurate recommendation is being considered according to the Riskiness of the recommending peer.

As discussed in Hussain et al [7] any recommending peer whose Riskiness value while giving recommendations is within the range of $(-1,1)$ is said to be a trustworthy recommending peer. So it is possible that the Riskiness value for the trusted peer ' $\mathrm{P}$ ' in a criterion ' $\mathrm{C}$ ' calculated from the trustworthy recommendations in equation 1 might come negative. We take the range of $(-1,1)$ to ascertain whether the recommendation is trustworthy or not and once it has been done, it should not have any further effect in determining the final Riskiness value of the trusted peer in a criterion by assimilating the recommendations. Hence we apply the mod operator in equation 1 to the first part of the equation which determines the Riskiness of a trusted peer ' $\mathrm{P}$ ' in a criterion ' $\mathrm{C}$ ' by taking the trustworthy recommendations.

In order to map the Riskiness value $\left(\mathrm{R}_{\mathrm{PC}}\right)$ of the trusted peer ' $\mathrm{P}$ ' in a criterion ' $\mathrm{C}$ ' on the riskiness scale (RS), it should be multiplied by 5 , as the Riskiness scale ranges from $(0,5)$ with -1 denoting Unknown 
Risk. Hence Riskiness value of the trusted peer ' $\mathrm{P}$ ' in a criterion ' $C$ ', mapped to the Riskiness scale ( $R_{\text {PRSC }}$ ) is:

$$
\mathrm{R}_{\mathrm{PRSC}}=\mathrm{ROUND}\left(\mathrm{R}_{\mathrm{PC}} * 5\right) \quad \text { Equation--------2 }
$$

When the Riskiness value for the trusted peer in each criterion of the trusting peer's interaction has been determined on the Riskiness scale by assimilating the recommendations, then its final Riskiness value in the interaction can be determined by weighing the individual Riskiness value of each criterion according to its significance, depending on the trusting peer. The levels of significance for each criterion $(\mathrm{Sc})$ are shown in table 1. All the criteria of an interaction will not be of equal importance or significance. Some criteria might play an important role in the completion of the interaction and some might not be as crucial as others. The significance of each criterion in an interaction might depend on the degree to which it influences the successful outcome of the interaction according to the trusting peer

Hence the final Riskiness value $\left(\mathrm{CR}_{\mathrm{p}}\right)$ of the trusted peer ' $\mathrm{P}$ ' as determined by the trusting peer ' $\mathrm{A}$ '

\begin{tabular}{|c|l|}
\hline $\begin{array}{l}\text { Significance level of } \\
\text { the Criterion }(\mathrm{Sc})\end{array}$ & $\begin{array}{l}\text { Significance Rating and } \\
\text { Semantics of the level }\end{array}$ \\
\hline 1 & Minorly Significant \\
\hline 2 & Moderately Significant \\
\hline 3 & Largely Significant \\
\hline 4 & Majorly Significant \\
\hline 5 & Highly or Extremely Signifcant \\
\hline
\end{tabular}

Table 1. Showing the significance level of each criterion

according to its criteria and significance of each criterion in the interaction by soliciting recommendations from other peers can be calculated as:

$$
\mathrm{CR}_{\mathrm{p}}=\operatorname{ROUND}\left(\frac{1}{\sum_{c=1}^{n} S_{c}}\left(\sum_{c=1}^{n} \mathrm{Sc} * \mathrm{R}_{\mathrm{PRSC}}\right)\right)
$$$$
\text { Equation----3 }
$$

where Sc represents the significance of the criterion 'c',

$\mathrm{R}_{\text {PRSC }}$ represents the Riskiness value of the trusted peer ' $\mathrm{P}$ ' in criterion ' $\mathrm{C}$ ' on the Riskiness scale (RS),

$\mathrm{n}$ is the number of criterions in the interaction.

It should be noted that the Riskiness value of the trusted peer ' $\mathrm{P}$ ' $\left(\mathrm{CR}_{\mathrm{p}}\right)$ determined by assimilating the recommendations should be set to 0 if it is less than 0 , as the Riskiness scale ranges from 0 to 5 with a value of -1 as Unknown Risk .

Finally when the trusting peer ' $A$ ' calculates the Riskiness values of the trusted peers ' $\mathrm{B}$ ' and ' $\mathrm{C}$ ' according to the criterions of its interaction by using the above proposed concept, then it can easily decide with which trusted peer to interact with depending on their Riskiness values.

The proposed concept will become clear when we explain by taking an example.

\section{Example of Decision Making by Analyzing the Riskiness of the Trusted Peers}

In this section we will explain with an example the process by which the trusting peer decides with which trusted peer to interact with, by assessing their Riskiness values according to the criteria and time of its interaction.

Let us consider the scenario mentioned in the previous section of the trusting peer ' $A$ ' having to decide from a set of trusted peers, with whom to interact with. The possible trusted peers in its interaction are peer ' $\mathrm{B}$ ' and peer ' $\mathrm{C}$ '. The trusting peer 'A' has not interacted with any of the possible trusted peers before and hence doesn't know the level of Risk that could be associated in dealing with any of them. Hence to analyze the Risk that could be present while interacting with each possible trusted peer it needs to determine the Riskiness of each peer according to the criteria and time of its interaction.

Let us suppose that the trusting peer wants to interact with a trusted peer on 14/08/2005 in context ' $\mathrm{C}$ ' and criterions $\mathrm{C} 1, \mathrm{C} 2$ and $\mathrm{C} 3$ and solicits for recommendations for peers ' $\mathrm{B}$ ' and ' $\mathrm{C}$ ' in the range of the past month. Hence the time space [5] is of one month. The trusting peer divides the time space into 2 time slots [5] each of 15 days i.e. one time slot from $14 / 07 / 2005$ to $29 / 07 / 2005$ and the second time slot from $30 / 07 / 2005$ to $13 / 08 / 2005$. Of the recommendations received in the two time slots from $14 / 07 / 2005$ to $13 / 08 / 2005$, the trusting peer should give more importance to the recommendations in the range of $30 / 07 / 2005$ to $13 / 08 / 2005$ as it is near to the time spot [5] of its interaction.

Let us suppose the recommendations that trusting peer 'A' gets for peer 'B' are:

From peer ' $D$ ':

\{Peer 'D', Peer 'B', Context 'C', 4, 4, ((C1, 1)(C3, $0)$ ), 3, 1000, 11/08/2005, 12/08/2005, -1 \}

From peer ' $E$ ':

\{Peer 'E', Peer 'B', Context 'C', 4, 3, $((\mathrm{C} 5,1)(\mathrm{C} 6$, 1)), 5, 500, 01/07/2005, 02/07/2005, UNKNOWN\}

Similarly recommendations for peer ' $\mathrm{C}$ ' are:

From peer ' $E$ ':

\{Peer 'E', Peer 'C', Context 'C', 3, 4, $((\mathrm{C} 5,1)(\mathrm{C} 6$, $0)), 4,200,1 / 08 / 2005,13 / 08 / 2005,1\}$

From peer 'F': 
$\{$ Peer 'F', Peer 'C', Context 'C', 5, 5, ((C2, 1)(C3, 1)), 4, 1200, 5/08/2005, 10/08/2005, 1 \}

From peer ' $G$ ':

\{Peer ' $G$ ', Peer 'C', Context 'C', 3, 3, $((\mathrm{C} 1,1)(\mathrm{C} 2$, 0)(C3,1)),5, 1500, 05/08/2005, 06/08/2005, -2.6\}

From peer ' $\mathrm{H}$ ':

\{Peer ' $\mathrm{H}$ ', Peer ' $\mathrm{C}$ ', Context 'C', 5, 5, $((\mathrm{C} 1,1)(\mathrm{C} 3$, 1)(C6,0)), 4,500,07/08/2005,07/08/2005, UNKNOWN\}

From peer 'I':

\{Peer 'I', Peer 'C', Context 'C', 2, 2, ((C1,1) $(\mathrm{C} 9,1)$ (C8, 0)), 1, 100, 30/07/2005, 02/08/2005, 1 \}

Classifying the recommendations for peer ' $\mathrm{B}$ ' as trustworthy, un-trustworthy or un-known depending on the Riskiness value of the recommending peer (RRP) and representing them according to their criteria in table 2:

\begin{tabular}{|l|l|c|}
\hline $\begin{array}{l}\text { Trustworthy } \\
\text { Recommendations }\end{array}$ & $\begin{array}{l}\text { Un-Known } \\
\text { Recommendations }\end{array}$ & $\begin{array}{l}\text { Un-Trustworthy } \\
\text { Recommendations }\end{array}$ \\
\hline Peer 'D' & Peer 'E' & None \\
C1(1), C3(0) & C5(1), C6(1) & \\
\hline
\end{tabular}

Table 2. Classifying the recommendations for peer ' $\mathrm{B}$ '

Similarly, classifying the recommendations for peer ' $\mathrm{C}$ ' as trustworthy, un-trustworthy or un-known depending on the Riskiness value of the recommending peers (RRP) and representing them according to their criteria in table 3 .

\begin{tabular}{|l|l|l|}
\hline Trustworthy & Un-Known & Un-Trustworthy \\
Recommendations & Recommendations & Recommendations \\
\hline Peer 'E' & Peer 'H' & Peer 'G' \\
C5(1), C6(0) & C1(1), C3(1), C6(0) & C1(1),C2(0), C3(1) \\
Peer 'F' & & \\
C2(1), C3(1) & & \\
Peer 'I' & & \\
C1(1), C9(1), C8(0) & & \\
\hline
\end{tabular}

Table 3. Classifying the recommendations for peer ' $\mathrm{C}$ '

As mentioned before the trusting peer while assimilating the recommendations considers only the trustworthy and unknown recommendations and discards the un-trustworthy recommendations. Hence it will take recommendations only from peers ' $D$ ', ' $E$ ' to determine the Riskiness value of peer ' $\mathrm{B}$ ' and from peer ' $E$ ', ' $F$ ', 'I' and ' $H$ ' to determine the Riskiness value of peer ' $\mathrm{C}$ ' according to the criteria of its interaction i.e. $\mathrm{C} 1, \mathrm{C} 2$ and $\mathrm{C} 3$. Let us suppose that the trusting peer ' $\mathrm{A}$ ' gives a weight of 0.9 to trustworthy recommendations and a weight of 0.1 to un-known recommendations, i.e. $\alpha$ and $\beta$ respectively. Further the trusting peer gives a weight of 0.6 to the recommendations, which are in the recent time slot of its interaction, and a weight of 0.4 to the far recent recommendations, i.e. $\gamma$ and $\delta$ respectively.

Hence assimilating the recommendations and determining the Riskiness value of the possible trusted peer ' $\mathrm{B}$ ' in the criterions of its interaction according to equation 1 :

Riskiness value of peer ' $B$ ' in criterion $C 1$ :

As there is only one recommendation for peer ' $\mathrm{B}$ ' in criterion $\mathrm{C} 1$ from trustworthy recommending peer ' $\mathrm{D}$ ', in the recent time slot of its interaction:

$\mathrm{R}_{\mathrm{BC} 1}=(0.9 *((|0.6(-1 * 1)|)+(|0.4 *(0)|)))+$

$(0.1 *((0.6 *(0))+(0.4 *(0))))$

$\mathrm{R}_{\mathrm{BC} 1}=0.54$

Representing it on the Riskiness scale by using equation 2:

$\mathbf{R}_{\text {BRSC1 }}=\operatorname{ROUND}(0.54 * 5)=3$

Riskiness value of peer ' $B$ ' in criterion $C 2$ :

There is no recommendation for peer ' $\mathrm{B}$ ' in criterion $\mathrm{C} 2$ from either a trustworthy or an unknown recommending peer. Hence according to the Riskiness scale the Riskiness value of the particular criterion will be -1 . Hence

$\mathrm{R}_{\mathrm{BRSC} 2}=\mathbf{- 1}$

Riskiness value of trusted peer ' $B$ ' in criterion C3:

There is one recommendation for peer ' $\mathrm{B}$ ' in criterion $\mathrm{C} 3$ from a trustworthy recommending peer ' $\mathrm{D}$ ', in the recent time slot of its interaction. Hence

$\mathrm{R}_{\mathrm{BC} 3}=(0.9 *((|0.6 *(-1 * 0)|)+(|0.4 *(0)|)))+$ $(0.1((0.6 *(0))+(0.4 *(0))))$

$\mathrm{R}_{\mathrm{BC} 3}=0$

Representing it on the Riskiness scale by using equation 2:

$\mathbf{R}_{\mathrm{BRSC} 3}=\mathbf{R O U N D}(\mathbf{0} * \mathbf{5})=0$

Assuming the significance of each criterion $\mathrm{C} 1, \mathrm{C} 2$ and $\mathrm{C} 3$ is 5 according to the trusting peer ' $\mathrm{A}$ '. Using equation 3 to determine the Riskiness value of the peer ' $\mathrm{B}$ ' in these criterions according to its significance:

$$
\begin{aligned}
& \mathrm{CR}_{\mathrm{B}}=\operatorname{ROUND}\left(\frac{1}{15}((5 * 3)+(5 *-1)+(5 * 0))\right) \\
& \mathrm{CR}_{\mathrm{B}}=\operatorname{ROUND}(0.66) \\
& \mathbf{C R}_{\mathbf{B}}=\mathbf{1}
\end{aligned}
$$

Hence the Riskiness value of peer ' $\mathrm{B}$ ' by assimilating the recommendations according to the criteria and time of the trusting peer ' $\mathrm{A}$ ' interaction is 1 on the Riskiness scale.

Similarly determining the Riskiness value of the possible trusted peer ' $\mathrm{C}$ ':

Riskiness value of peer ' $C$ ' in criterion $\mathbf{C} 1$ :

There is one recommendation for peer ' $\mathrm{C}$ ' in criterion $\mathrm{C} 1$ from each a trustworthy recommending peer ' $I$ ' and an unknown recommending peer ' $\mathrm{H}$ ', in the recent time slot of its interaction. Hence

$$
\begin{aligned}
& \mathrm{R}_{\mathrm{CC} 1}=(0.9 *((|0.6 *(1 * 1)|)+(|0.4 *(0)|)))+ \\
& (0.1((0.6 *(1))+(0.4 *(0)))) \\
& \mathrm{R}_{\mathrm{CC} 1}=0.6
\end{aligned}
$$


Representing it on the Riskiness scale by using equation 2:

\section{$\mathbf{R}_{\mathrm{CRSC} 1}=$ ROUND $(0.6 * 5)=3$}

Riskiness value of peer ' $C$ ' in criterion $C 2$ :

There is one recommendation for peer ' $\mathrm{C}$ ' in criterion $\mathrm{C} 2$ from trustworthy recommending peer ' $\mathrm{F}$ ', in the recent time slot of its interaction. Hence

$\mathrm{R}_{\mathrm{CC} 2}=(0.9 *((|0.6 *(1 * 1)|)+(|0.4 *(0)|)))+$ $(0.1 *((0.6 *(0))+(0.4 *(0))))$

$\mathrm{R}_{\mathrm{CC} 2}=0.54$

Representing it on the Riskiness scale by using equation 2:

$\mathbf{R}_{\mathrm{CRSC} 2}=$ ROUND $(0.54 * 5)=3$

Riskiness value of peer ' $C$ ' in criterion $C 3$ :

There is one recommendation for trusted peer ' $\mathrm{C}$ ' in criterion $\mathrm{C} 3$ from each a trustworthy recommending peer ' $\mathrm{F}$ ' and an unknown recommending peer ' $\mathrm{H}$ ', in the recent time slot of its interaction:

$\mathrm{R}_{\mathrm{CC} 3}=(0.9 *((|0.6 *(1 * 1)|)+(|0.4 *(0)|)))+$ $(0.1((0.6 *(1))+(0.4 *(0))))$

$\mathrm{R}_{\mathrm{CC} 3}=0.54+0.06=0.6$

Representing it on the Riskiness scale by using equation 2:

$\mathbf{R}_{\text {CRSC } 3}=\operatorname{ROUND}(0.6 * 5)=3$

Using equation 3 to determine the Riskiness value of the peer ' $\mathrm{C}$ ' according to the criterions

$$
\begin{aligned}
& \mathrm{CR}_{\mathrm{C}}=\operatorname{ROUND}\left(\frac{1}{15}\left(\left(5^{*} 3\right)+\left(5^{*} 3\right)+(5 * 3)\right)\right) \\
& \mathrm{CRc}=\operatorname{ROUND}(3) \\
& \mathbf{C R}_{\mathbf{c}}=\mathbf{3}
\end{aligned}
$$

Hence the Riskiness values of peers ' $\mathrm{B}$ ' and ' $\mathrm{C}$ ' as determined by the trusting peer ' $\mathrm{A}$ ' by assimilating the recommendations according to the time slot and criteria of its interaction are 1 and 3 respectively on the Riskiness scale. Based on the Riskiness values the trusting peer can decide with which trusted peer to interact with.

From the above example it can be seen that the criteria of the recommendations from peer ' $E$ ' for peer ' $C$ ' are not similar to those of the trusting peer ' $A$ ' and hence in spite of the recommendations being trustworthy, they were not considered by trusting peer ' $A$ ' while determining the Riskiness value of the trusted peer ' $C$ '. Similarly the recommendation from recommending peer ' $G$ ' was un-trustworthy and the trusting peer ' $A$ ' disregarded it when determining the Riskiness value of peer ' $C$ '.

\section{Conclusion}

In this paper we highlighted a problem that is common in peer-to-peer e-commerce transactions. It is possible that the trusting peer might have to decide and choose from a set of trusted peers, with which peer to interact with. We proposed a solution to the process of decision making by analyzing the Risk that could be associated in dealing with each possible trusted peer beforehand according to the context, criteria and time of the trusting peer's interaction. The peer whose Riskiness value represents the lowest Risk on the Riskiness scale can be chosen as the trusted peer to interact with. The trusting peer can determine the Riskiness value of each trusted peer by soliciting for its recommendations and later assimilating them according to its criteria in the interaction. Finally we concluded the paper by explaining the process of decision making according to the context, criteria and time with an example.

\section{References}

[1] O.K. Hussain, E. Chang, F.K.Hussain, T.S. Dillon and B. Soh, "Risk in Trusted Decentralized Communications", Proceedings of the International Workshop on Privacy Data Management in Conjunction with 21st International Conference on Data Engineering (ICDE PDM 2005), pp 63-67, Tokyo , Japan , 9 April 2005.

[2] D.F. Cooper, 'The Australian and New Zealand Standard on Risk Management, AS/NZS 4360:2004', Tutorial Notes: Broadleaf Capital International Pty Ltd., 2004 Available: http://www.broadleaf.com.au/tutorials/Tut_Standard.pdf

[3] S. Greenland, 'Bounding analysis as an inadequately specified methodology', Risk Analysis, vol. 24, no. 5, pp. 1085-1092, 2004.

[4] O.K. Hussain, E. Chang, F.K.Hussain and T.S. Dillon, "A Methodology for Risk Measurements in e-Transactions", Special issue of International Journal of Computer System, Science and Engineering, CRL publishing Ltd, UK., To be published in March/April 2006.

[5] O.K.Hussain, E.Chang, F.K.Hussain, T.S.Dillon and B.Soh, "Context and Time Based Riskiness Assessment for Decision Making", (Accepted for Publication) International Conference on Internet and Web Applications and Services (ICIW 2006), Guadeloupe, French Caribbean, February 23-25, 2006.

[6] O.K Hussain, E.Chang, F.K. Hussain, T.S. Dillon and B. Soh, "Modeling the Risk Relationships and Defining the Risk Set" Proceedings of CollECTeR Latam 2005, Chile, 3-5 October 2005.

[7] O.K Hussain, E.Chang, F.K. Hussain, T.S. Dillon and B. Soh, "Context Based Riskiness Assessment", Proceedings of IEEE TENCON 2005, pp. 352-356, Melbourne, November 22-24 2005. 